\title{
ARTHROPOD RESPONSE TO PRAIRIE MANAGEMENT ON RECLAIMED MINE LAND IN APPALACHIA ${ }^{1}$
}

\begin{abstract}
Alexys K. Nolan², Keiron Young, and Rebecca M. Swab
Abstract. Prescribed burning and mowing are common management techniques in prairie ecosystems; however, more information is need ed to understand the full effects of these practices on resident arthropods. To study these impacts and understand how they relate to arthropod assemblages on reclaimed coalmine land, an arthropod trapping project was conducted in the summer of 2017 at The Wilds in southeast Ohio. Pitfall trapping was used on four prairies which had undergone different management techniques in recent years: 1) burned in the spring a few months before the study, 2) burned in the spring a year prior to the study, 3) mowed late summer the year before the study, and 4) no recent management. Results showed that all prairies that received management treatments had a family richness of 41-44, while the unmanaged prairie had a family richness of 33. The mowed prairie had the highest arthropod abundance and the lowest family diversity; contrarily, the recent 2017 burned prairie had the lowest abundance and the highest family diversity. The two dominant guilds in all treatments were detritivorecarrion feeding arthropods and predator-parasite arthropods; these guilds were proportioned similarly in all treatments except for the 2017 burned prairie, which was the only treatment to have a significantly higher proportion of predatorparasites than detritivore-carrion feeders. This evidence indicates that detritivorecarrion feeding arthropods are more negatively impacted by recent fire than predator-parasites, though within these groups the response of individual taxonomic families differed. Overall findings indicate that while mowing prairies may result in higher abundances of arthropods and relatively high levels of family richness, it may not increase family diversity. Prescribed fire appears to have a negative impact on arthropod abund ance initially; however, the higher abund ance of arthropods in the 2016 burned prairie indicates that burned grasslands can be recolonized relatively quickly. It is recommended that periodic burning is done to maintain the grassland ecosystem and sustain arthropod richness and diversity. In areas where burning is not practical, rotational mowing can be used to sustain richness and increase arthropod abundance.
\end{abstract}

Additional Key Words: Insect; Burning; Prescribed Fire; Mowing; Mechanical; Entomobryidae; Coleoptera; Porcellionid ae; Lycosidae; Orbatid Mite; Formicidae

1. This paper was submitted to JASMR for consideration in one of their issues and was not presented at our conferences that were held in the past.

2. Alexys K. Nolan, Restoration Ecology Program Associate, The Wilds, Cumberland, OH 43732; Keiron Young, Restoration Ecology Apprentice, The Wilds; Rebecca Swab, Director of Restoration Ecology, The Wilds.

DOI: http://dx.doi.org/10.21000/JASMR20010029 


\section{Introduction}

Tallgrass prairies are an important ecosystem, though they have significantly diminished since the European settlement of North America (Samson and Knopf, 1996). They provide nectar resources for insects, habitat for birds, and host unique plant species that have become adapted to disturbances such as fire and grazing (Allen and Palmer, 2011). When these disturbances are excluded from prairies, these ecosystems become colonized by trees and shrubs and begin to undergo succession (Nowacki and Abrams, 2008; Weir and Scasta, 2017). To prevent this, burning and mowing have become common maintenance practices by prairie land managers. The impacts of these common prairie management techniques on some wildlife species, especially pollinators, have been well studied (Swengel and Swengel, 2001; Campbell et al., 2007; Grant et al., 2010; Lettow et al., 2018); however, arthropod species and community assemblages can vary widely between locations, and further investigation is needed to understand the nuanced responses of arthropods to ecosystem management.

Investigations into arthropod response to prescribed fire, in particular, have had greatly varied results and are often highly nuanced. Differences in arthropod responses to fire may be partially explained by the patchiness of the burns and the overall burn coverage (Shuey, 1997; Panzer, 2002), as well as the individual responses of different arthropod orders to prairie management. Some orders of arthropods may benefit from these practices while others are negatively affected (Reed, 1997). Panzer (2003) found that adult Coleopteras are able to burrow into the ground and increase their chance of survival. Bell et al. (2001) and Karuse and Assmann (2016) expand on this principal regarding Aranae. They showed that ground dwelling hunting spiders, which can also bury underground, benefit from tallgrass prairie burns and the increases in food availability that follows; alternatively, they found that web spinning spider populations were much more adversely affected. Other studies have shown further negative impacts of burning and heavy grazing, as the implementation of these practices were followed by a significantly lower density of flying arthropods such as Orthoptera and Diptera (Van Amburg et al., 1981; Fay, 2003). These varying responses to fire ultimately alter the proportions of different species in the overall arthropod communities, favoring some and hindering others, and creating a new community assemblage (New, 2014). The makeup of this new assemblage is difficult to predict, though it is generally accepted that most taxa will recover with time (New, 2014). 
Arthropod recovery may be affected by how damaging the fire was to larvae and eggs, as there may be a negative effect on those laid on grasses or in ground litter (Harper et al., 2000). Timing of the burn may also contribute, as Barratt et al. (2009) speculate that spring grassland burning may allow for arthropod regeneration in that same year before winter; however, summer burns that take place during the crucial stage of the arthropod mating period may hinder population regeneration the following year. However, a study by Johnson et al. (2008) found contrary evidence that prairie areas burned in the summer supported $170 \%$ more individual arthropods than winter burns, with a significantly higher number of carnivorous arthropods than those that are herbivorous.

Studiesfocused on the effects of mowing practices on arthropod populations have shown fewer variable results than burning. It is evident that herbivorous insects heavily rely on healthy plant communities, meaning effective management of plant communities allows these grasslands to support larger populations of insects (Stoner and Joern, 2004). The general consensus seems to be that rotational mowing of grasslands is recommended, meaning that half of the site should be mowed at one time, then the other half mowed later on in order to provide a refuge (Noordijk et al., 2010; Mazalova et al., 2015). Summer cuts should also be avoided if at all possible due to the timing of insect life cycles (Bell et al., 2001; Mazalova et al., 2015). Noordijk et al. (2010) added that even leaving small vegetation refuges intact after mowing events may be beneficial; a focus on localized cutting of brush may also be favorable over broadcast mowing for some species (Swengel et al., 2011). Mazalova et al. (2015) found that less mobile groups (i.e., groups without the ability to fly), were negatively impacted in mowed areas, while populations of highly mobile groups (e.g., Coleptera, Diptera, Lepidoptera) tended to increase in cut areas.

It is clear that many studies have worked to elucidate the effects of different grassland management techniques on arthropod taxa, but there are still gaps in knowledge; for example, little is known about arthropod communities in novel ecosystems, in particular prairies planted on the historically forested Appalachian region of the United States. Surface coal mining in Appalachia has resulted in the disturbance of over 970,000 hectares of forests, which, under the federal Surface Mining Control and Reclamation act of 1977, have largely been reclaimed to non-native, cool season grasslands (Adams, 2017). In some areas, efforts to restore native species to the landscape have resulted in the conversion of cool season grasslands to warm season tallgrass prairies. 
The overall objectives of this experiment are to study the populations of arthropods in warm season prairie grasslands on a reclaimed coal mine to determine whether or not management techniques affect the family diversity, richness, abundance, and community assemblages of arthropod populations. To make these determinations, arthropods were captured using live and lethal traps from burned, mowed, and control prairie sites at The Wilds, a reclaimed mine site in southeastern Ohio. The results of this study will likely guide future prairie management practices on site, and hopefully inform prairie management on other reclaimed mine lands in the region.

\section{Methods}

\section{$\underline{\text { Site Selection }}$}

All sites were located on the property of The Wilds, a 3,705-hectare conservation, research, and education center in southeast Ohio (Fig. 1). The general location of our study is $39.828249 \mathrm{~N}$, -81.719986W. The Wilds landscape was historically strip mined for coal and reclaimed, which reshaped the vegetation communities entirely. Reclamation efforts between 1973-1984 revegetated the landscape with many non-native and some invasive species, namely cool season grasses such as tall fescue (Festuca arundinacea) and Kentucky bluegrass (Poa pratensis), forbs such as sericea lespedeza (Lespedeza cuneata Dumont-Cours) and birdsfoot trefoil (Lotus corniculatus), and the shrub autumn olive (Eleagnus umbellata Thunberg). Approximately 283 hectares of these reclaimed grasslands were broadly treated with nonselective herbicide and replanted with native prairie species between 1999 and 2016. Plantings followed the guidelines of the Environmental Quality Incentives Program of the Natural Resources Conservation Service.

Arthropod responses to prairie plantings and prairie management on reclaimed coal mine lands have not yet been documented. All prairies sampled in this experiment are formerly mined areas that received different management treatments in the five years prior to arthropod sampling (Table 1). Beetle Prairie had undergone a spring burn in the same year as arthropod sampling (2017 burned), Admin Prairie was burned in the spring of the year prior (2016 burned), and International had been mowed the summer before this study. Willow had not undergone recent management, allowing it to serve as a baseline for comparison. All prairies in this experiment were in close proximity to each other and were converted from cool season grasslands between 2010 and 2012, meaning the influence of management practices likely influenced arthropod populations more than factors such as geography and prairie age. 


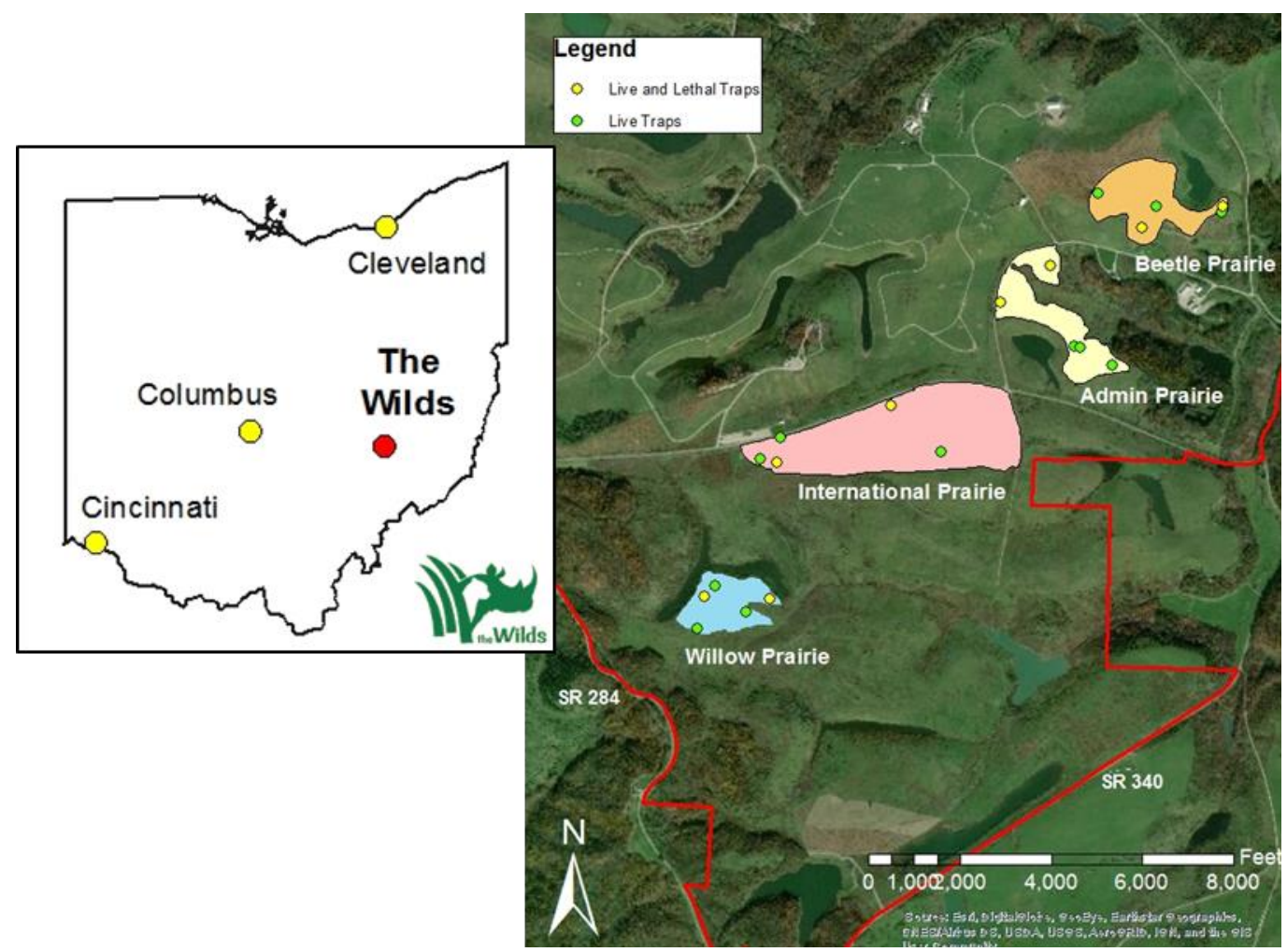

Figure 1. Left: Wilds location in Ohio. Right: map of prairie locations and arthropod trapping points at The Wilds.

Table 1. Prairie size, management type, year of initial reclamation as grassland and year of conversion to prairie.

\begin{tabular}{lllll}
\hline Prairie & Hectares & Management & Yr. Reclamation & Yr. Planting \\
\hline Admin & 12.5 & Burn (Mar. 2016) & $1978-1979$ & 2011 \\
Beetle & 10.1 & Burn (Feb. 2017) & 1981 & 2010 \\
International & 44.5 & Mow (Aug. 2016) & $1978-1979$ & 2012 \\
Willow & 18.2 & None since 2012 & 1982 & 2011 \\
\hline
\end{tabular}

\section{$\underline{\text { Sampling Design and Trapping }}$}

Coordinates for trap placement within the four sites were chosen randomly using ArcGIS 10.5

(Fig. 1). Twenty pitfall traps were deployed, or five traps per treatment, and each one was sampled on 12 different days. The traps used in this experiment were based on designs used by Melbourne (1999); they were designed to catch terrestrial arthropods and selectively exclude undesired organisms such as mammals and amphibians. A $0.95 \mathrm{~L}$ plastic food container (sleeve) was placed into a hole dug out with a golf hole cutter; the sleeve was flush with ground level. A second 0.95L container (trap) was placed inside the sleeve, which held the trap approximately $15-20 \mathrm{~mm}$ above ground level, thus rainwater would not flow into the trap and drown subjects. A lip of soil was 
built around the rim of the top container to allow arthropods to walk into the trap. A piece of $2.54 \mathrm{~cm}$ wire mesh was then placed flush with the surface of the trap to prevent small vertebrates from being trapped. A polystyrene plate situated above the mesh $30 \mathrm{~mm}$ from the soil surface was secured by wooden skewers to shelter traps from precipitation. No lethal agent was used during the first eight days of trapping, which took place May 16th through May 19th and May 30th through June 2nd of 2017. Upon collection, the arthropods were euthanized in a 1:8 ratio mix of 200 proof ethanol and water. The traps were sealed between trapping periods.

A second period of daily arthropod trapping and collection was conducted from June 12th through June 16th of 2017. During this four day stretch, lethal traps were used; this was done by placing the ethanol-euthanizing agent within the trap. Due to concern about the critically endangered American Burying Beetle (Nicrophorus americanus), which had been recently released on site as part of a reintroduction program, a second $2.54 \mathrm{~cm}$ wire mesh grate was placed over the trap during lethal trapping to prevent unwanted species from falling into the trap. The second layer of mesh reduced the openings to $0.64 \mathrm{~cm}$, a size smaller than the beetles could fit through. It is unlikely that any arthropod species besides the American Burying Beetle were excluded by the smaller opening, as the live traps with a larger opening were deployed on site before the lethal traps, with zero instances of capturing arthropods that would have been too large to fit through the smaller grate. After arthropods were collected, they were stored in ethanol and later identified undera dissection microscope at 3.5-90x magnification. Specimens were identified to the lowest possible taxonomic group.

\section{Data Analysis}

Raw arthropod community data was analyzed in R Studio 1.0.136 (2009-2016). ANOVA tests were run in $\mathrm{R}$ to compare live and lethal trapping data to ensure that different trap data could be pooled. The ANOVA tests compared arthropod abundance (the number of individuals within the trap types), species richness (the total number of different species within the traps), and species diversity (richness, abundance, and evenness within the traps). Diversity was calculated using Shannon's diversity index taken from Morris et al. (2014). Tukey Post Hoc tests were used to determine which sites had significant differences.

Further analyses in Excel (2016) compared family taxa between treatments, determining family richness (number of different families) and family diversity (richness, abundance, and 
evenness using Shannon diversity index). Families were then sorted into trophic groups, or guilds, according to Borror et al. (1989) in order to determine changes in general assemblages between treatments. Grouping by trophic guilds can be useful, as they tend to be controlled by different driving forces (Simão et al., 2015; Pan et al., 2018). This assessment was done using chi-tests in Excel. Due to the low sample size of the other guilds, we only statistically compared proportions of the two dominate guilds, predator-parasites and detritivore-carrion feeders, between treatments (see Appendix I).

\section{$\underline{\text { Results }}$}

A total of 5395 individual arthropods were captured in the 12 trapping days and identified to the lowest possible taxonomic group; 103 of these were identified only to order, 90 of which were locust/grasshopper larva (Orthoptera) and 10 were worms (Megadrilacea). Of these individuals, 2002 were from live pitfall traps and 3351 from lethal pitfall traps; the mean number of arthropods found in each live and lethal trap each day was $61.28 \pm 46.28$ and 208.19 \pm 148.25 , respectively. While there were no significant differences found between live and lethal trap species diversity and richness $(p>0.05)$ abundance did change by trap type $(p=0.001)$ (Table 2$)$. The lethal traps in the Mow 2016 treatment were the only ones with significantly higher abundance than the live traps $(\mathrm{p}<0.05)($ Table 3$)$.

Table 2. ANOVA comparison of arthropod abundance, diversity, and species richness between live and lethal traps.

\begin{tabular}{llllll}
\hline ANOVA test & DF & Sum sq & Mean sq & F value & P value \\
\hline Live vs. lethal abundance & 7 & 809562 & 115652 & 5.353 & $1.43 \mathrm{E}-3$ \\
Live vs. lethal diversity & 7 & 0.0625 & 0.008926 & 0.476 & 0.84 \\
Live vs. lethal richness & 3 & 742.4 & 106.05 & 2.19 & 0.0801 \\
\hline
\end{tabular}

Table 3. Tukey Post Hoc comparison of arthropod abundance between live traps vs. lethal traps for prairie treatment.

\begin{tabular}{lllll}
\hline Tukey post hoc test & Difference & Lower & Upper & P Adj. value \\
\hline Burn 2016 live vs. lethal traps & -381.1 & -795.7 & 33.5 & 0.09 \\
Burn 2017 live vs. lethal traps & -77.9 & -492.5 & 336.7 & 0.99 \\
Mow 2016 live vs. lethal traps & -477.4 & -892 & -62.8 & 0.02 \\
No management live vs. lethal traps & -184.7 & -599.3 & 229.9 & 0.80 \\
\hline
\end{tabular}

\section{Abundance, Diversity, and Richness by Site}

When assessing family data and grouping live and lethal trapping data, 1765 arthropods were captured in the 2016 burn treatment, 421 in the 2017 burn treatment, 2236 in the mowed treatment, and 870 in the unmanaged treatment. Family richness was 41-44 for the three sites that received 
management and 33 for the unmanaged treatment (Table 4). Family diversity was highest in the 2017 burn treatment and lowest in the 2016 mow treatment, while 2016 burn. and unmanaged treatments were nearly identical. (Table 4).

Table 4. Arthropod abundance, family richness, and family diversity by treatment; proportions of trophic guilds within each treatment.

\begin{tabular}{lcccc}
\hline Indices & Burn 2016 & Burn 2017 & Mow 2016 & No Management \\
\hline Totalarthropods & 1765 & 421 & 2236 & 870 \\
Relative abundance & 0.33 & 0.08 & 0.42 & 0.16 \\
Family Richness & 41 & 44 & 43 & 33 \\
Avg. Family Richness per day & $13.91 \pm 3.60$ & $11.08 \pm 5.23$ & $13.58 \pm 3.96$ & $10.58 \pm 2.15$ \\
Shannon diversity (family) & 2.21 & 2.91 & 1.73 & 2.24 \\
Evenness & 0.59 & 0.77 & 0.46 & 0.64 \\
Relative abundance of trophic & & & & \\
groups within each treatment: & & & & \\
$\quad$ Predator-parasite & 0.39 & 0.62 & 0.39 & 0.37 \\
$\quad$ Detritivore-carrion & 0.56 & 0.29 & 0.59 & 0.59 \\
$\quad$ Omnivore & 0.04 & 0.04 & 0.01 & 0.03 \\
$\quad$ Herbivore & 0.005 & 0.03 & 0.001 & 0.001 \\
$\quad$ Sucking & 0.004 & 0.009 & 0.004 & 0.01 \\
$\quad$ Pollinator & 0.002 & 0.009 & 0.001 & 0.00 \\
\hline
\end{tabular}

Arthropod Assemblages

Arthropod trophic guilds followed consistent trends in each treatment, with 56-59\% of each population being detritivore or carrion feeders, 37-39\% falling into the predator-parasite guild, and 2-5\% falling into herbivore, omnivore, pollinator, or sucking guilds (Table 4). The exception to this is the 2017 burned prairie, which had more predator-parasite specimens (62\%) than detritivore-carrion (29\%) or other specimens (9\%). Chi square comparisons showed that these differences in predator-parasite/detritivore-carrion guild proportions were significant between the 2017 burn treatment and all other treatments $(\mathrm{p}<0.05)$ (Table 5). There were no statistical differences between the proportions of those guilds in other site assemblages. The other trophic group samples were either too small or two skewed for chi square analysis.

Table 5. Chi square association test comparing the proportions of the two dominant arthropod guilds, Predator-parasites and Detritivore-Carrion feeders, between each of the different prairie management treatments.

\begin{tabular}{llll}
\hline Sites compared & $\boldsymbol{\chi 2}$ & df & p-value (significance $\mathrm{p}<0.05)$ \\
\hline Burn 2016 and Mow 2016 & 0.3986 & 1 & 0.5278 \\
Burn 2016 and No management & 1.1775 & 1 & 0.2779 \\
Burn 2017 and Burn 2016 & 95.914 & 1 & $1.1996 \mathrm{E}-22$ \\
Burn 2017 and Mow 2016 & 108.66 & 1 & $1.9301 \mathrm{E}-25$ \\
Burn 2017 and No management & 93.959 & 1 & $3.2207 \mathrm{E}-22$ \\
Mow 2016 and No management & 0.3948 & 1 & 0.5298 \\
\hline
\end{tabular}


The most commonly captured arthropod families in the detritivore-carrion guild were Entomobryidae, Porcellionidae, and Poduridae (Fig. 2). Within the detritivore-carrion guild, the 2016 burned and mowed treatments were both proportionally dominated by Entomobryidae ( $>50 \%$ ), while the unmanaged treatment was dominated by Porcellionidae (45\%), and dominance in the 2017 burned treatment was fairly equally divided between Dicyrtomidae (25\%), Entomobryidae (22\%), and Porcellionidae (21\%). The most common predator-parasite families were Formicidae, Lycosidae, and Humerobatidae (Fig. 3). Within the pred ator-parasite guild, both the 2016 burned and mowed treatments were dominated by Formicidae (50\% and 73\%, respectively), while the unmanaged treatment was split equally between Formicidae (40\%) and Lycosidae (42\%), and the 2017 burn treatment was relatively equally divided between Formicidae (22\%), Lycosidae (21\%), and Humerobatidae (21\%).

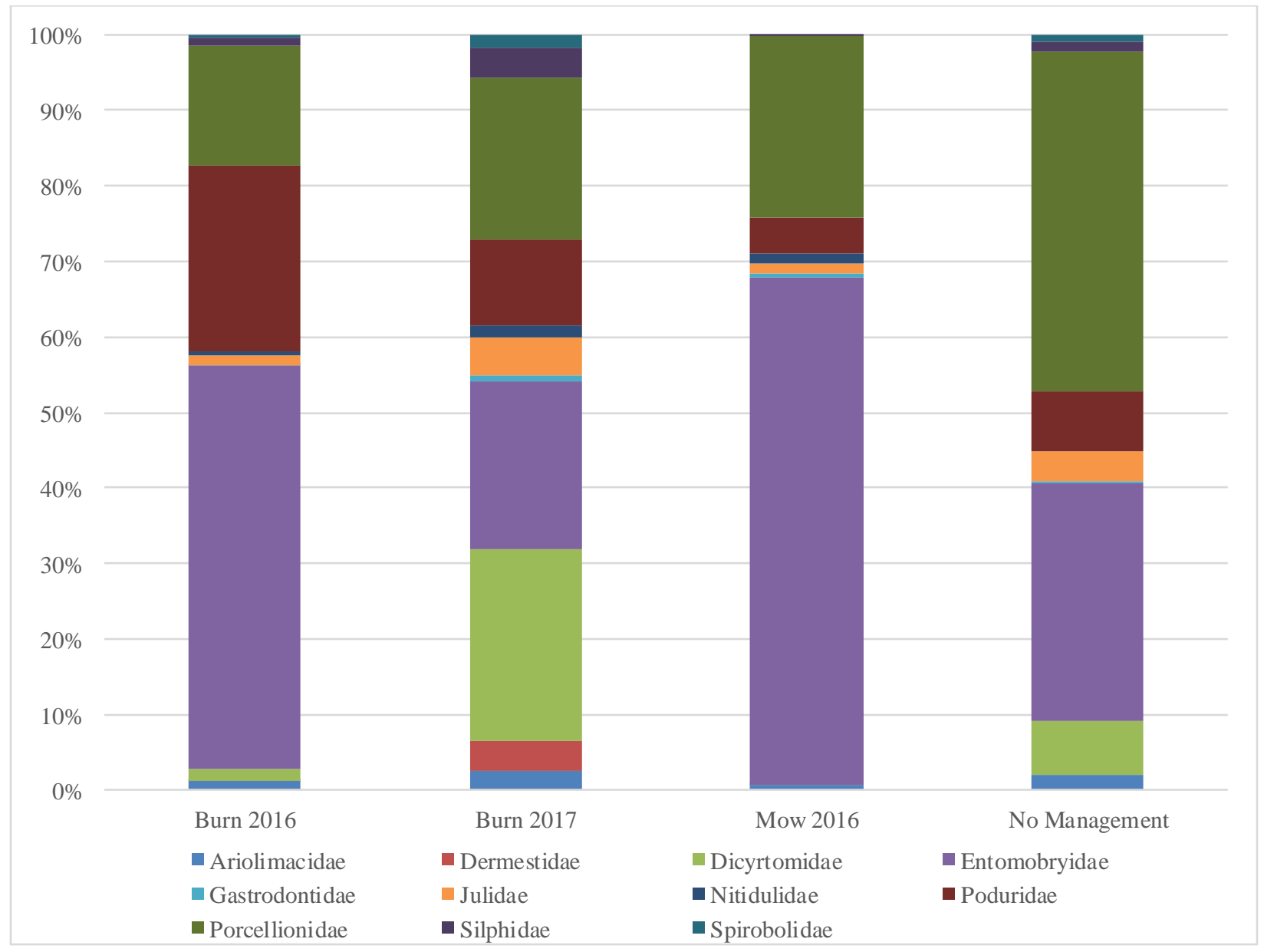

Figure 2. Proportional breakdown of families that made up the detritivore-carrion guild in four differently managed prairies. 


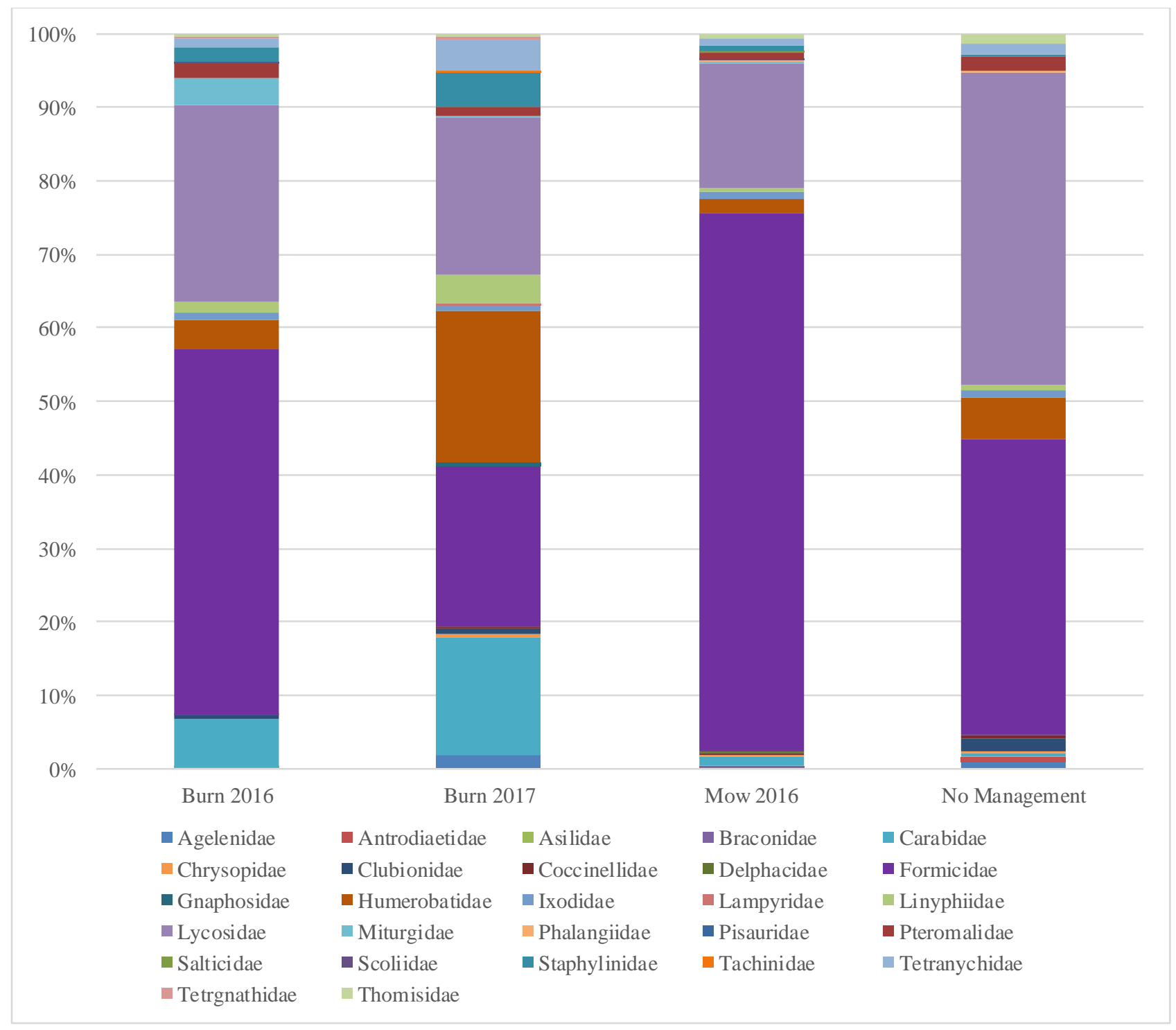

Figure 3. Proportional breakdown of families that made up the predator-parasite guild in four differently managed prairies.

\section{$\underline{\text { Discussion }}$}

\section{$\underline{\text { Abundance, Diversity, and Richness }}$}

Arthropod abundance was higher in the mowed prairie than any other, potentially as a result of high amounts of plant biomass available on the ground (Prather and Kaspari, 2019). Interestingly, however, diversity was lowest in the mowed treatment. This could be a result of high arthropod mortality, and could potentially have been avoided by leaving refuges or mowing in intervals (Noordijk et al., 2010; Mazalova et al., 2015). The 2017 burned prairie had the lowest abundance of all sites, likely due to mortality; high levels of arthropod mortality following a 
prescribed burn have been recorded (Swengel et al, 2011). Despite the considerably low abundance immediately following the burn, the less recent 2016 burned treatment had a high relative abundance of arthropods. This shows that arthropod mortality may be substantial in prairie burns, but it is possible for their populations to regenerate relatively quickly after burning.

Despite the low relative abundance of arthropods in the 2017 burned prairie, the family richness in this treatment was consistent with the other prairies that received management. The unmanaged prairie had the lowest family richness of all treatments, which matches expectations. Unmanaged prairie likely makes poorer quality habitat for arthropods, as structural heterogeneity of grassland vegetation increases with management - a factor that increases arthropod richness (Joern, 2004; Weiss et al., 2013). Lack of disturbance in prairie ecosystems can also lead to decreased diversity of the plant community (Gross and Romo, 2010), a factor which has been linked to decreases in arthropod diversity (Haddad et al., 2011). This is contrary to our findings, however, as even though the unmanaged prairie had the lowest family richness, the overall family diversity was higher than the mowed prairie. To better understand these find ings, future arthropod surveys should be coupled with vegetation surveys that document overall plant diversity, percent cover type (i.e., percent grasses, forbs, shrubs, etc.), and variation in total plant percent cover.

\section{Arthropod Assemblages}

Arthropod assemblages usually change when fire is used on the land scape, though the nature of these changes are site specific and difficult to generalize (New, 2014). As predicted in the literature, arthropod assemblages were proportionally different in the 2017 burned prairie compared to the unmanaged prairie (Reed, 1997; Bell et al., 2001; Karuse and Assman, 2016; Driessen and Kirkpatrick, 2017). In fact, when classifying arthropods by guild, the proportions of the 2017 burned site were different from the guild proportions in all other prairies; namely, the predator-parasites dominated the 2017 burned site, while the detritivore-carrions dominated at all other sites, including the less recent 2016 burned site. This may indicate that burning has an initial, short-term overall impact on assemblages, and a larger negative impact on some individual species or groups compared to others. It would appear that the detritivore-carrion feeding arthropods were negatively affected by burning at a disproportionately high level compared to predator-parasites. We suggest that several of these species may be more susceptible to fire, or that the available food resources (decaying plant and fungi matter) for detritivore-carrion feeding arthropods were reduced greatly by fire, or a combination of the two. This, coupled with the traits that some 
predator-parasite possess (e.g., high mobility, ability to burrow into the soil) may have favored their survival or recolonization, and may have been responsible for the high proportion of predatorparasites in the 2017 burned site compared to others.

$\underline{\text { Response of Detritivore-carrion Feeders to Fire. Although Collembola springtails (Entomobryidae }}$ and Poduridae) largely dominated the detritivore-carrion group in the 2016 burned and the mowed prairie, they had much lower abundance in the 2017 burned area, suggesting they were heavily impacted by recent burning. Large decreases in Collembola abund ance afterburning has also been documented by Harper et al. (2000). The apparent recovery of Entomobryidae springtails in the 2016 burned prairie is potentially consistent with the findings of Malmström (2012), who observed recovery of one Entomobrya spp. after burning, though the Entomobryidae in our experiment were only identified to genus so it is unknown if these were the same species. Another type of springtail, the globular springtail (Dicyrtomidae) had no observed differences in abundance afterfire, which is also similar to Malmströms findings. Because globular springtail abundance was similar in all treatments, it made up a higher proportion of the overall detritivore-carrion group in the 2017 burned prairie compared to others. These two examples of springtail response to fire are not necessarily representative of springtails in general, many other springtails tend to be slow to recover after fire, some not recovering after 10-12 years (Brand, 2002; Malmström, 2012). The main factors that may predict Collembola recovery, apart from severity of the burn, are species traits such as fast active dispersal ability and sexual rather than asexual reproduction (Malmström, 2012).

Little information was available regarding other detritivore-carrion feeders' response to fire. We found that wood lice (Porcellionidae) capture was much less frequent in the 2017 burned prairie compared to other treatments. This decreased abundance is likely due to direct mortality from the burn; isopods are notoriously sensitive to humidity and lose water rapidly in low humidity environments (Dias et al., 2012). It is possible that woodlice burrowed under the soil or hidden under cover objects during burning may still have experienced desiccation as local temperature increased and humidity decreased, though further research is needed to explore this notion considering the typically short duration of fire over any give spot. Other detritivores, such as slugs (Ariolimacedae), snails (Gastrodontidae), millipedes (Julidae and Spriobolidae), and beetles (Dermestidae, Nitidulidae and Silphidae), were less frequently caught across all prairie treatments, so we were unable to assess their responses to management. 


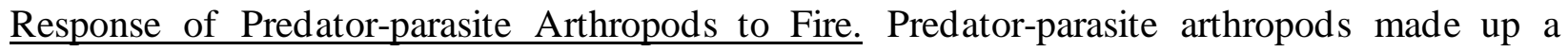
significantly larger proportion of arthropods trapped in the 2017 burned prairie compared to all other treatments, potentially due to different species-specific traits such as ability to move more quickly and avoid fire, natural tendency to use hiding places, and increased dispersal and colonization capability. The proportion of wolf spiders (Lycosidae) within the predator-parasite guild was relatively consistent in all treatments. The tendency for wolf spiders to hide under naturally protective structures such as rock formations and in the soil (Bell et al., 2001) may have helped them survive the burn more successfully than other arthropods. Pardosa wolf spiders in particular, which comprised approximately half of the wolf spider species captured in this study, may have been able to survive the burn better and/or recolonize faster than other species. They are known to prefer wetter areas (Bradley, 2010) and may have been living in areas where the burn was naturally patchier or less intense. More compelling evidence showed that Pardosa occurred twice as frequently in burned sites and are generally rapid colonizers of disturbed ground (Bell et al., 2001; Karuse and Assman, 2016).

While ants (Formicidae) were the most abundant predator in all treatments, they were disproportionately more affected by the 2017 burned than other families in the predator-parasite classification. Morantz et al. (2013) have suggested that the response of ant colonies to disturbance varies depending on the presence or absence of dominant ant species; if a dominant species is present, they may outcompete other generalist ant species and reduce their ability to quickly recolonize burned areas. Alternatively, population reductions after management may be attributed to mortality of ant prey species during the burn (Morantz et al., 2013). Because ants in this study were not identified to species we cannot comment on the former, however it is possible that ant prey reduction played a role in the lower abundance observed here.

The primary Coleoptera captured, rove beetles (Staphylinidae) and ground beetles (Carabidae), were found in both higher numbers and higher proportions of the predator-parasite guild in both burned prairies compared to mowed and unmanaged prairies (Fig. 6). The typical ability of Coleoptera to burrow into the ground may have contributed to this, as they may have been able to protect themselves during the burn, surviving in larger numbers (Panzer, 2003). The high agility and activity of rove beetles may also have allowed them to escape the burn or quickly colonize the burned prairies. 
Predatory orbatid soil mites (Sarcoptiformes) are generally very widespread and can colonize new areas quickly by phoresis on other insects (Navarro et al., 2019; Coulson, 2009). As such, it is not surprising that they made up a higher proportion of the predator guild in the 2017 burned prairie than in other treatments. In fact, almost twice as many individuals were captured in the 2017 burned prairie than in all other treatments. These findings are not unheard of, and have been attributed to higher temperatures in the prairie during the first growing season after burning, and potentially also a result of decreased soil moisture during the growing season (Lussenhop, 1976). A replication of this study should take a temperature and moisture measurement at each trapping site throughout the trapping period to better understand the relationship between environmental changes between treatments and their effects on soil micro-arthropods.

Omnivore Response to Fire. Omnivore populations made up 1-4\% of arthropods captured in all prairies, almost all of which were crickets (Gryllidae) and unidentified grasshopper/locust larva from order Orthoptera. Notably, grasshopper species were captured least in the 2017 burned prairie, similar to the findings of Chambers and Samways (1998) and Fay (2003); however, this study primarily reflects larva response to management rather than adults and grasshoppers overall. To achieve a more complete picture of grasshopper response to management, a continuation of this study that includes visual counts or sweep netting is recommended.

\section{$\underline{\text { Land Use History and Other Considerations }}$}

All prairies in this study were historically mined, reclaimed in different years, and converted to prairie between 2010 and 2012 (Table 1). Some of the differences in populations could potentially be attributed to the inherent site differences. Certain prairies may not have established as well as others when they were converted due to variations in soil, herbicide effectiveness at killing off cool season grasses, and timing of each step in the conversion process. The result of this may be lower quality habitat for arthropods due to lower plant diversity and less structural heterogeneity (Weiss et al., 2013) that is unrelated to management exercises. Because vegetation

surveys were not done in any of these prairies prior to or post management, these underlying conditions affecting habitat quality are not known. It is recommended that this study is further built upon by collecting additional years of arthropod, vegetation, and environmental data at these sites. 
In addition to inherent site differences, the patchiness of the burns may affect arthropod mortality and regeneration (Swengel et al., 2011). In some studies, certain species are only able to rebuild their populations if unburned patches exist nearby, and others (springtail species) experienced deleterious effects 10 years post-burn in a study that did not purposely leave refuges (Swengel et al., 2011; Malmström 2012). Intensity of burns affects the patchiness, and the two burned prairies in this study certainly experienced different fire intensities, burn crews considered the 2016 burn smokier and less intense, while the 2017 burn was more intense and less patchy, potentially contributing to the lower arthropod abundance in the 2017 burned site.

The final component to consider is the limitation of pitfall trapping. This method was used to limit the impacts on end angered species on site, but it can have biases and may not have gotten the full picture of arthropod assemblages (Melbourne, 1999; Ward et al., 2001). Additional survey techniques such as sweep netting, spider web misting, or visual surveys would be useful in subsequent surveys to supplement pitfall data.

\section{Conclusions}

Prairies have been shown to be viable landcovers that establish native vegetation on reclaimed minelands (Swab et al., 2017). Prairie management is necessary to maintain ecosystem integrity (Weir and Scasta, 2017), and this can affect arthropod communities. In this case, mowing appears to have a positive impact on arthropod abund ance and family richness, and it has been shown that this form of management can achieve the desired reduction of woody plant encroachment (Van Dyke et al., 2004). Although mowing alone is not as beneficial for plant communities as prescribed burning (Rooney, 2010), and may not promote arthropod family diversity, it can be an effective substitute in areas where burning is not a safe or reasonable practice, especially if done rotationally or in a manner that leaves unmowed refuges (Noordijk et al., 2010; Mazalova et al., 2015).

Prairie management via burning may have high arthropod mortality initially; however, this practice appears to benefit family richness and diversity, and in a relatively short period of time, the burned prairie can be recolonized. Arthropod assemblages were affected by burning, with some families reacting positively and others negatively, thus it may be best to follow a management plan that integrates mowing and burning techniques at different intervals (Swengel and Swengel, 2001). Overall, some form of periodic grassland management is recommended to preserve family richness and promote diversity. 


\section{$\underline{\text { Acknowledgements }}$}

Taylor Snelick for data analysis guid ance. Andrea Malek and Wilds apprentices for assistance with trapping. Juston Wickham for leading the prescribed burns, and various Wilds staff, apprentices, and local volunteer firefighters for their assistance with the burns. Thanks to reviewers for anonymous suggestions.

\section{Literature Cited}

Adams, M.B. 2017. The forestry reclamation approach: guide to successful reforestation of mined lands. Gen. Tech. Rep. NRS-169. Newtown Square, PA: US Department of Agriculture, Forest Service, Northern Research Station: 128 p. https://doi.org/10.2737/NRSGTR-169

Allen, M.S. and M.W. Palmer. (2011). Fire history of a prairie/forest boundary: more than 250 years of frequent fire in a North American tallgrass prairie. Journal of Vegetation Science. 22: 436-444. https://doi.org/10.1139/z68-049

Barratt, B.I.P., C.M. Fergusson, D.M. Barton, and P.D. Johnstone. (2009). Impact on fire on tussock grassland invertebrate populations. Science for Conservation. 291.

Bell, J.R., P.C. Wheater, and R.W. Cullen. (2001). The implications of grassland and heathland management for the conservation of spider communities: a review. Journal of Zoology. 255(3): 377-387. https://doi.org/10.1017/S0952836901001479

Borror, D.J., C.A. Triplehorn, and N.F. Johnson. (1989). Introduction to the study of insects. Saunders College Pub, $6^{\text {th }}$ edition.

Bradley, R.A. (2010). Common spiders of Ohio field guide. Ohio Department of Natural Resources: Division of Wild life. Publication 5140: 41-45.

Brand, R.H. (2002). The effect of prescribed burning on epigeic springtails (Insecta: Collembola) of woodland litter. The American Midland Naturalist. 148(2): 383-393. https://doi.org/10.1674/0003-0031(2002)148[0383:TEOPBO]2.0.CO;2

Campbell, J.W., J.L. Hanula, and T.A. Waldrop. (2007). Effects of prescribed fire and fire surrogates on floral visiting insects of the blue ridge province in North Carolina. Biological Conservation. 134: 393-404. https://d oi.org/10.1016/j.biocon.2006.08.029

Chambers, B.Q. and M.J. Samways. (1998). Grasshopper response to a 40-year experimental burning and mowing regime, with recommendations for invertebrate conservation 
Journal American Society of Mining and Reclamation, 2020 Vol.9, No 1

$\begin{array}{llll}\text { management. } \quad \text { Biodiversity } & \text { and }\end{array}$ https://doi.org/10.1023/A:1008803513740

Coulson, S.J. (2009). Association of the soil mite Diapterobates notatus (Thorell, 1871) (Acari, Oribatidae) with Cynomya mortuorum (Linnaeus, 1761) (Calliphoridae, Calliphorinae): implications for the dispersal of orbatid mites. International Journal of Acarology. 35(2): 175177. https://doi.org/10.1080/01647950902934242

Dias, N., M. Hassall, and T. Waite. (2012). The influence of microclimate on foraging and sheltering behaviors of terrestrial isopods: implications for soil carbon dynamics under climate change. Pedobiologia International Journal of Soil Biology. 55: 137-144. https://doi.org/10.1016/j.pedobi.2011.10.003

Driessen, M.M. and J.B. Kirkpatrick. (2017). The implications of succession after fire for the conservation management of moorland invertebrate assemblages. Journal of Insect Conservation. 21: 15-37. https://doi.org/10.1007/s10841-016-9948-9

Fay, P.A. (2003). Insect diversity in two burned and grazed grasslands. Entomological Society of America. 32(5): 1099-1104. https://doi.org/10.1603/0046-225X-32.5.1099

Grant, T.A., E.M. Madden, T.L. Shaffer, and J.S. Dockens. (2010). Effects of prescribed fire on vegetation and passerine birds in northern mixed grass prairie. Journal of Wildlife Management. 74(8): 1841-1851. https://doi.org/10.2193/2010-006

Gross, D.V. and J.T. Romo. (2010). Burning history, time of burning, and year effects on plant community structure and heterogeneity in fescue prairie. Botany. 88: 1-12. https://doi.org/10.1139/B09-091

Haddad, N.M., G.M. Crutsinger, K. Gross, J. Haarstad, and D. Tilman. (2011). Plant diversity and the stability of foodwebs. Ecology Letters. 14: 42-46. https://doi.org/10.1111/j.14610248.2010.01548.x

Harper, M.G., C.H. Dietrich, R.L. Larimore, and P.A. Tessene. (2000). Effects of prescribed fire on prairie arthropods: an exclosure study. Natural Areas Journal., 20: 235-335.

Joern, A. (2004). Variation in grasshopper (Acrididae) densities in response to fire frequency and bison grazing in tallgrass prairie. Environmental Entomology. 33(6): 1617-1625. https://doi.org/10.1603/0046-225X-33.6.1617

Johnson, S.D., K.C. Horn, A.M. Savage, S. Windhager, M.T. Simmons, and J.A. Rudgers. (2008). Timing of prescribed burns affects abundance and composition of arthropods in the Texas Hill 
country. The Southwestern Naturalist. 53(2): 137-145. https://doi.org/10.1894/00384909(2008)53[137:TOPBAA]2.0.CO;2

Karuse, R.H. and T. Assmann. (2016). Impact of prescribed burning on a heathland inhabiting spider community. Arachnology Letters. 51: 57-63. https://doi.org/10.5431/aramit5108

Lettow, M.C., L.A. Brudvig, C.A. Bahlai, J. Gibbs, R.P. Jean, and D.A. Landis. (2018). Bee community responses to a gradient of oak savanna restoration practices. Restoration Ecology. 26(5): 882-890. https://doi.org/10.1111/rec.12655

Lussenhop, J. (1976). Soil arthropod response to prairie burning. Ecology. 57: 88-98. https://doi.org/10.2307/1936400

Malmström, A. (2012). Life-history traits predict recovery patterns in Collembola species after fire: a 10-year study. Applied Soil Ecology. 56: 35-42. https://doi.org/10.1016/j.apsoil.2012.02.007

Mazalova, M., J. Sipos, S. Rada, J. Kasak, B. Sarapatka, and T. Kuras. (2015). Responses of grassland arthropods to various biodiversity-friendly management practices: is there a compromise? European Journal of Entomology. 112(4): 734-746. https://doi.org/10.14411/eje.2015.076

Melbourne, B.A. (1999). Bias in the effect of habitat structure on pitfall traps: an experimental evaluation. Australian Journal of Ecology. 24: 228-239. https://doi.org/10.1046/j.14429993.1999.00967.x

Morantz, R.A., D.M. Debinski, L. Winkler, J. Trager, D.A. McGranahan, D.M. Engle, and J.R. Miller. (2013). Effects of grassland management practices on ant functional groups in central North America. Journal of Insect Conservation. 17: 699-713. https://doi.org/10.1007/s10841$\underline{013-9554-Z}$

Morris, K.E., T. Caruso, F. Buscot, M. Fischer, C. Hancock, T.S. Maier, T. Meiners, C. Muller, E. Obermaier, D. Prati, S.A. Socher, I. Sonnemann, N. Waschke, T. Wubet, S. Wurst, and M.C. Rillig. (2014). Choosing and using diversity indices: insights for ecological applications from the German Biodiversity Exploratories. Ecology and Evolution. 18(4): 3514-3524 https://d oi.org/10.1002/ece3.1155

Navarro, M.J., F.R. López-Serrano, L.A. Esucdero-Colomar, and F.J. Gea. (2019). Phoretic relationship between the myceliophagous mite Microdispus lambi (Acari: Microdispidae) and 
mushroom flies in Spanish crops. Annals of Applied Biology. 174: 277-283. https://doi.org/10.1111/aab.12498

New, T.R. (2014). Insects, fire and conservation. Springer International Publishing Switzerland, eBook. https://d oi.org/10.1007/978-3-319-08096-3

Noordijk, J., A.P. Schaffers, T. Heijerman, P. Boer, M. Gleichman, and K.V. Sykora. (2010). Efforts of vegetation management by mowing on ground-dwelling arthropods. Ecological Engineering. 36(10): 740-750. https://doi.org/10.1016/j.ecoleng.2010.01.003

Nowacki, G.J. and M.D. Abrams. (2008). The demise of fire and "mesophication" of forests in the Eastern United States. BioScience. 58(2): 123-138. https://doi.org/10.1641/B580207

Pan, C., Q. Feng, L. Jiliang, Y. Li, Y. Li, and X. Yu. (2018). Community structure of grassland ground-dwelling arthropods along increasing soil salinities. Environmental Science and Pollution Research. 25: 7479-7486. https://doi.org/10.1007/s11356-017-1011-1

Panzer, R. (2002). Compatibility of prescribed burning with the conservation of insects in small, isolated prairie reserves. Conservation Biology. 16: 1296-1307. https://doi.org/10.1046/j.1523-1739.2002.01077.x

Panzer, R. (2003). Importance of in-situ survival, recolonization, and habitat gaps in the postfire recovery of fire-sensitive prairie insect species. Natural Areas Journal. 23: 14-21.

Prather, R.M. and M. Kaspari. (2019). Plants regulate grassland arthropod communities through biomass, quality, and habitat heterogeneity. Ecosphere. 10(10). https://doi-org.mu.opallibraries.org/10.1002/ecs2.2909

Reed, C. (1997). Response of prairie insects and other arthropods to prescription burns. Natural Areas Journal. 17(4): 380-385.

Rooney, T.P. and M.K. Leach. (2010). Replacing hay-mowing with prescribed fire restores species diversity and conservation value in a tallgrass prairie sampled thrice: a 59-year study. The American Midland Naturalist. 164(2): 311-321. https://doi.org/10.1674/0003-0031-164.2.311

Samson, F.B. and F.L Knopf. (1996). Prairie conservation: preserving North America's most end angered ecosystem. Island Press. 13.

Shuey, J.A. (1997). Dancing with fire: ecosystem dynamics, management, and the Karner blue (Lycaeides malissa samelis Nabokov) (Lycaenidae). Journal of The Lepidopterists' Society. 51: 263-269. 
Simão, F.C.P., M.A. Carretero, M.J.A. Amaral, A.M.V. Soares, and E. Mateos. Composition and seasonal variation of egigeic arthropods in field margins of NW Portugal. (2015). Turkish Journal of Zoology. 39: 404-411. https://doi.org/10.3906/zoo-1401-69

Stoner, K.J. and A. Joern. (2004). Landscape vs. local habitat scale influences to insect communities from tallgrass prairie remnants. Ecological Applications. 14(5): 1306-1320. https://doi.org/10.1890/03-5112

Swab, R.M., N. Lorenz, S. Byrd, and R. Dick. (2017). Native vegetation in reclamation: Improving habitat and ecosystem function through using prairie species in mine land reclamation. Ecological Engineering. 108: 525-536. https://doi.org/10.1016/j.ecoleng.2017.05.012

Swengel A.B. and S.R. Swengel. (2001). Effects of prairie and barrens management on butterfly faunal composition. Biodiversity and Conservation. 10: 1757-1785. https://doi.org/10.1023/A:1012051510584

Swengel, S.R., D. Schlicht, F. Olsen, and A.B. Swengel. (2011). A literature review of insect responses to fire, compared to other conservation managements of open habitat. Biodiversity and Conservation. 10:1141-1169. https://d oi.org/10.1023/A:1016683807033

Van Amburg, G.L., J.A. Swaby, and R.H. Pemle. (1981). Response of arthropods to a spring burn of a tallgrass prairie in Northwest Minnesota. Ohio Biological Survey. 15: 240-243.

Van Dyke, F., S.E. Van Kley, C.E. Page, and J.G. Van Beck. (2004). Restoration efforts for plant and bird communities in tallgrass prairies using prescribed burning and mowing. Restoration Ecology. 12(4): 575-585. https://doi.org/10.1111/j.1061-2971.2004.00352.x

Ward, D.F., T.R. New, and A.L. Yen. (2001). Effects of pitfall trap spacing on the abundance, richness and composition of invertebrate catches. Journal of Insect Conservation. 5: 47-53. https://doi.org/10.1023/A:1011317423622

Weir, J.R. and J.D. Scasta. (2017). Vegetation responses to season of fire in tallgrass prairie: a 13 year case study. Fire Ecology. 13(2): 137-142. https://doi.org/10.4996/fireecology.130290241

Weiss, N., H. Zucchi, and A. Hochkirch. (2013). The effects of grassland management and aspect on Orthoptera diversity and abundance: site conditions are as important as management. Biodiversity and Conservation. 22: 2167-2178. https://d oi.org/10.1007/s10531-012-0398-8

\section{$\underline{\text { Appendix }}$}

Appendix I. Guild classification of all arthropod families and the number of times they were captured in the four prairie treatments. 
Journal American Society of Mining and Reclamation, 2020 Vol.9, No 1

\begin{tabular}{|c|c|c|c|c|c|}
\hline Family & Guild classification & Burn 2016 & Burn 2017 & Mow 2016 & No Management \\
\hline Acanthosomatidae & Sucking & 1 & 0 & 0 & 0 \\
\hline Agelenidae & Predator & 1 & 5 & 2 & 3 \\
\hline Antrodiaetidae & Predator & 0 & 0 & 0 & 2 \\
\hline Aphididae & Sucking & 2 & 1 & 3 & 1 \\
\hline Apidae & Pollinator & 0 & 0 & 1 & 0 \\
\hline Ariolimacidae & Detritivore & 12 & 3 & 8 & 10 \\
\hline Asilidae & Predator & 1 & 0 & 0 & 0 \\
\hline Braconidae & Parasite & 0 & 0 & 1 & 0 \\
\hline Cantharidae & Pollinator & 0 & 1 & 0 & 0 \\
\hline Carabidae & Predator & 45 & 42 & 12 & 2 \\
\hline Cerambycidae & Herbivore & 2 & 5 & 0 & 0 \\
\hline Chrysomelidae & Herbivore & 1 & 0 & 0 & 0 \\
\hline Chrysopidae & Predator & 0 & 1 & 1 & 1 \\
\hline Cicadidae & Sucking & 2 & 3 & 1 & 0 \\
\hline Clubionidae & Predator & 2 & 2 & 0 & 5 \\
\hline Coccinellidae & Predator & 0 & 1 & 2 & 2 \\
\hline Culicidae & Omnivore & 5 & 6 & 2 & 5 \\
\hline Curculionidae & Herbivore & 0 & 1 & 0 & 0 \\
\hline Cydnidae & Sucking & 0 & 0 & 0 & 6 \\
\hline Delphacidae & Predator & 1 & 0 & 3 & 0 \\
\hline Dermestidae & Detritivore & 1 & 5 & 0 & 0 \\
\hline Dicyrtomidae & Detritivore & 15 & 31 & 2 & 37 \\
\hline Elateridae & Omnivore & 0 & 2 & 2 & 0 \\
\hline Entomobryidae & Detritivore & 530 & 27 & 890 & 162 \\
\hline Formicidae & Predator & 338 & 57 & 637 & 129 \\
\hline Gastrodontidae & Detritivore & 2 & 1 & 6 & 1 \\
\hline Geocoridae & Sucking & 0 & 0 & 2 & 0 \\
\hline Gnaphosidae & Predator & 0 & 1 & 0 & 0 \\
\hline Gryllidae & Omnivore & 66 & 8 & 19 & 19 \\
\hline Humerobatidae & Predator & 28 & 54 & 16 & 18 \\
\hline Ixodidae & Parasite & 6 & 2 & 10 & 3 \\
\hline Julidae & Detritivore & 12 & 6 & 20 & 21 \\
\hline Lampyridae & Predator & 0 & 1 & 0 & 0 \\
\hline Latridiidae & Omnivore & 1 & 0 & 1 & 1 \\
\hline Limnephilidae & Herbivore & 0 & 0 & 0 & 1 \\
\hline Linyphiidae & Predator & 10 & 10 & 3 & 2 \\
\hline Lycosidae & Predator & 183 & 56 & 149 & 136 \\
\hline Membracidae & Sucking & 0 & 0 & 3 & 2 \\
\hline Miridae & Sucking & 3 & 0 & 1 & 0 \\
\hline Miturgidae & Predator & 25 & 1 & 1 & 0 \\
\hline Mordellidae & Pollinator & 3 & 3 & 1 & 0 \\
\hline Nitidulidae & Detritivore & 5 & 2 & 16 & 0 \\
\hline Noctuidae & Pollinator & 0 & 0 & 1 & 0 \\
\hline Phalangiidae & Predator & 0 & 0 & 2 & 1 \\
\hline Pisauridae & Predator & 0 & 0 & 1 & 0 \\
\hline Poduridae & Detritivore & 245 & 14 & 64 & 40 \\
\hline Porcellionidae & Detritivore & 157 & 26 & 318 & 232 \\
\hline Pteromalidae & Parasite & 13 & 3 & 8 & 6 \\
\hline Salticidae & Predator & 0 & 0 & 1 & 0 \\
\hline Scarabaeidae & Herbivore & 0 & 2 & 1 & 0 \\
\hline Scoliidae & Parasite & 1 & 0 & 0 & 0 \\
\hline Silphidae & Carrion & 12 & 5 & 2 & 6 \\
\hline Simuliidae & Omnivore & 0 & 0 & 1 & 0 \\
\hline Spirobolidae & Detritivore & 3 & 2 & 0 & 5 \\
\hline Staphylinidae & Predator & 13 & 12 & 7 & 1 \\
\hline
\end{tabular}


Journal American Society of Mining and Reclamation, 2020 Vol.9, No 1

\begin{tabular}{llllll} 
Symphyta & Herbivore & 3 & 1 & 0 & 0 \\
Tachinidae & Parasite & 0 & 1 & 0 & 0 \\
Tenebrionidae & Omnivore & 0 & 1 & 0 & 0 \\
Tetranychidae & Parasite & 9 & 11 & 8 & 5 \\
Tetrgnathidae & Predator & 2 & 1 & 0 & 0 \\
Tettigoniidae & Herbivore & 0 & 2 & 0 & 4 \\
Thomisidae & Predator & 2 & 1 & 6 & 1 \\
Thyreocoridae & Sucking & 0 & 0 & 0 & 0 \\
Tipulidae & Omnivore & 0 & 1 & 0 & 0 \\
Trogossitidae & Herbivore & 1 & 0 & 0 & 0 \\
Zopheridae & Herbivore & 1 & 0 & 1 & 0 \\
\hline
\end{tabular}

